\title{
An Evolutionary Model of Endogenous Business Cycles
}

\author{
GIOVANNI DOSI, ${ }^{1}$ GIORGIO FAGIOLO ${ }^{2}$ and ANDREA ROVENTINI ${ }^{3}$ \\ ${ }^{1}$ Sant'Anna School of Advanced Studies, Laboratory of Economics and Management, Piazza \\ Martiri della Libertà, I-56127 Pisa, Italy; E-mail: gdosi@sssup.it \\ ${ }^{2}$ University of Verona, Italy and Sant'Anna School of Advanced Studies, Pisa, Italy \\ ${ }^{3}$ Sant'Anna School of Advanced Studies, Pisa, Italy and University of Modena and Reggio Emilia, \\ Italy
}

\begin{abstract}
In this paper, we present an evolutionary model of industry dynamics yielding endogenous business cycles with 'Keynesian' features. The model describes an economy composed of firms and consumers/workers. Firms belong to two industries. The first one performs R\&D and produces heterogeneous machine tools. Firms in the second industry invest in new machines and produce a homogenous consumption good. Consumers sell their labor and fully consume their income. In line with the empirical literature on investment patterns, we assume that the investment decisions by firms are lumpy and constrained by their financial structures. Moreover, drawing from behavioral theories of the firm, we assume boundedly rational expectation formation. Simulation results show that the model is able to deliver self-sustaining patterns of growth characterized by the presence of endogenous business cycles. The model can also replicate the most important stylized facts concerning micro- and macro-economic dynamics. Indeed, we find that investment is more volatile than GDP; consumption is less volatile than GDP; investment, consumption and change in stocks are procyclical and coincident variables; employment is procyclical; unemployment rate is anticyclical; firm size distributions are skewed but depart from log-normality; firm growth distributions are tent-shaped.
\end{abstract}

Key words: evolutionary dynamics, agent-based computational economics, animal spirits, lumpy investment, output fluctuations, endogenous business cycles

JEL Classifications: C15, C22, C49, E17, E22, E32.

\section{Introduction}

The existence of widespread and persistent fluctuations which permanently affect the overall economic activity is an inherent feature of all modern economies. However, despite the huge number of competing models providing a rationale for expansions and recessions, we still lack a generally accepted explanation for business fluctuations. Indeed, it still holds largely true that a good deal of research has been mainly concerned with 'theoretical possibilities, rather than with explanations of what actually happens,' with 'little regard for how the pieces fit each other and the real world' (Zarnowitz, 1985, p. 570). Ultimately, the theory of business cycle appears to be 'long of both good and poor questions and short of persuasive answers' (Zarnowitz, 1997, p. 2). 
A primary example of such a mismatching might be found in the ways economic theory deals with the stylized facts concerning microeconomic investment dynamics and business cycle properties. A robust macroeconomic empirical literature has indeed shown that, at the aggregate level, investment is considerably more volatile than output and consumption less volatile. Moreover, fluctuations of both output and its main components (i.e. investment, consumption and changes in inventories) tend to be synchronized. Finally, at the microeconomic level, firms' investments appear to be lumpy and strongly affected by firms' financial structures.

Needless to say, one does indeed find huge streams of work on business cycles mostly belonging either to the Real Business Cycle (RBC) perspective or to the New-Keynesian (NK) one. This is not the place to undertake a review of the literature (on RBC, cf. King and Rebelo (1999) and Stadler (1994); on NK theories, see Mankiw and Romer (1991) and Greenwald and Stiglitz (1993)). Let us just mention here the basic mechanisms generating cycles in the two perspectives. Real-business cycles are ultimately driven by exogenous and unpredictable technological shocks, which generate fluctuating dynamics in a stochastic general-equilibrium world, grounded upon a fully-rational, forward-looking representative agent. Conversely, the basic story of NK models finds the roots of economic fluctuations in product-, labor- and financial-market imperfections (including in primis informational asymmetries). At the same time, these models do allow for some heterogeneity, at least in the functional roles of the agents (the economy is in fact populated by financial investors, firms, consumers, etc.), even if under the disguise of 'representative', fully rational types.

Certainly, one finds very hard to believe the existence of macroscopic technological shocks (including negative ones) necessary for the RBC story to hold. ${ }^{1}$ And, conversely, while the informational setting of NK models is much more reasonable, we still feel uneasy about the almost exclusive emphasis upon monetary and price shocks as drivers of the fluctuations, while neglecting all technological factors.

Moreover, in our view, a major weakness - shared to different degrees by both streams of literature - is the persistent clash between the microeconomics that one finds in the models and the regularities in microeconomic behaviors that one empirically observes. So, for example, notwithstanding the proliferation of models separately trying to account for micro and macro stylized facts, almost no attempts have been made in the literature to explain the properties of business cycles on the basis of multiple individual entities embodying the observed microeconomic regularities about firms' investment and pricing behaviors.

In this paper, we try to bridge such a gap by proposing a model where both output and investment dynamics are grounded upon lumpy investment decisions undertaken by boundedly-rational firms constrained by their financial structure, but, at the same time, always able to discover new production technologies. 
First, we fully take on board the critique to the 'representative agent fallacies' (Kirman, 1989, 1992) and describe an economy with heterogeneous agents that interact in explicitly modeled markets.

Second, well in line with Keynesian intuitions, we assume pervasive market uncertainty, so that investment and pricing decisions are taken on the grounds of boundedly-rational rules, most often involving adaptive expectations. In turn, such decisions bear permanent aggregate demand effects.

Conversely, third, the 'Schumpeterian' feature of the model regards the persistent arrival of technological innovations, entailing multiple endogenously generated micro-shocks on productivity.

The model depicts an economy composed by firms (operating in two verticallylinked industries), consumers/workers and a (unmodeled) non-market sector. Firms in the 'upstream' industry perform R\&D and produce technologically heterogeneous machines. The latter are used in the 'downstream' industry to produce a consumption good bought by workers with their wages and by recipients of incomes in the non-market sector.

The work belongs to the evolutionary, 'agent-based computational economics' (ACE), family. ${ }^{2}$ In each period $t$, firms and workers carry out their production, investment, and consumption decisions on the basis of routinized behavioral rules and (adaptive) expectations. The dynamics of microeconomic variables (i.e. individual production, investment, consumption, etc.) thus induces the macroeconomic dynamics for aggregate variables (e.g. aggregate output, investment, consumption, etc.), whose statistical properties are then studied and compared with empirically observed ones.

Simulation results show that the model is able to deliver self-sustaining growth patterns characterized by endogenous business cycles. Moreover, we show that the model is able to replicate those business cycle stylized facts (e.g. volatility, autoand cross-correlation patterns) actually observed. Finally, the micro-structure of the simulated economy is quite in tune with the evidence on e.g. persistent heterogeneity in firm efficiencies, size and growth rate distributions.

The rest of the paper is organized as follows. Section 2 provides a short overview of micro and macro empirical evidence. In Section 3, we discuss the antecedents and theoretical roots of our model, which we formally present in Section 4. Qualitative and quantitative results of simulation exercises are discussed in Section 5. Section 6 concludes.

\section{Aggregate Fluctuations and Micro Regularities: Some Evidence}

To repeat, a good check of the robustness of any model claiming to be able to 'explain' business cycles ought to rest in its ability to account together for more than one macroeconomic 'stylized fact' and ought to do it in ways which are coherent with the observed microeconomics of business decisions and innovation patterns. Let us thus consider the most relevant empirical regularities. 


\subsection{MACRO STYLIZED FACTS}

A key issue in the empirical business cycle literature concerns the properties of aggregate output and of its main components (i.e. investment, consumption and inventories).

All available statistical evidence suggests that recurrent fluctuations have characterized the whole history of industrial economies. This applies also to the period after WWII, when aggregate output and its main components have experienced an impressive long term growth in the U.S. as well as in other developed countries. Even then, however, time-series display growth together with persistent 'cyclical' turbulences. This can be seen also if the dynamics of output and its components is analyzed at the business cycle frequencies: there, the series display a typical 'roller coaster' shape, implying the repeated interchange of expansions and recessions which are part of the very definition of the business cycle. ${ }^{3}$

Thus, the evidence pre- and post-WWII - which we summarize in Table Icorroborates the seminal observations dating back to Kuznets (1930) and Burns and Mitchell (1946), suggesting the following stylized facts: ${ }^{4}$

SF1 Investment is considerably more volatile than output.

SF2 Consumption is less volatile that output.

SF3 Investment, consumption and change in inventories tend to be procyclical and coincident variables. $^{5}$

SF4 Aggregate employment and unemployment rate tend to be lagging variables. The former is procyclical, whereas the latter is anticyclical.

\subsection{MICRO STYLIZED FACTS}

Over the last couple of decades, the empirical literature on industrial dynamics and technological change has singled out an impressive number of robust statistical regularities concerning the microeconomic properties of firm behavioral patterns. Let us begin here with a telegraphical account of those stylized facts pertaining to firms' investment decisions.

SF5 Investment is lumpy.

SF6 Investment is influenced by firms' financial structure.

Consider first SF5. As shown by the important work of Doms and Dunne (1998) based on U.S. plant level data, lumpiness is an intrinsic feature of firm investment decisions: in a given year, $51.9 \%$ of all plants increase their capital stock by less than $2.5 \%$, while the $11 \%$ of them raise it by more than $20 \%$. Moreover, withinplant investment patterns show that plants typically invest in every single year, but they concentrate half of their total investment in just three years out of the sixteen under analysis.

Moreover, the microeconomic lumpiness of investment does not appear to be completely filtered away at the macroeconomic level. Aggregate investment 
AN EVOLUTIONARY MODEL OF ENDOGENOUS BUSINESS CYCLES

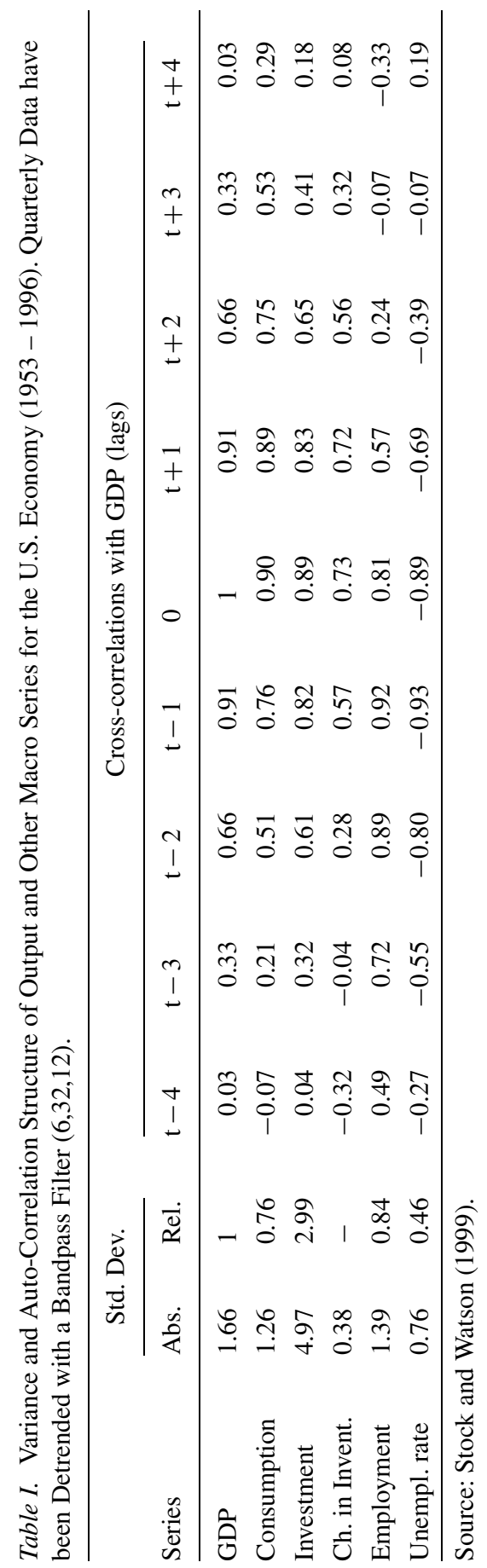


fluctuations are indeed influenced by the number of plants incurring huge investment episodes: the correlation between aggregate investment and the number of plants experiencing their maximum investment share is 0.59 .

As far SF6 is concerned, the evidence is even more impressive. Since the influential work of Fazzari, Hubbard, and Petersen (1988), a huge stream of empirical literature ${ }^{6}$ has been providing evidence against the Modigliani and Miller (1958) theorem. Indeed, if capital markets are imperfect (e.g. because of information asymmetries), the financial structure of the firm is likely to affect its investment decisions. First, the cost of external financing is typically higher than that of internal financing: the larger information costs born by each firm, the higher the gap between the cost of internal and external financing. Second, information asymmetries may lead lenders to ration credit to the riskiest firms. These propositions are supported by the evidence provided by the so-called 'financial constraints' literature: ceteribus paribus, firm investment is significantly correlated with cash flows (a proxy for net worth variations) and the correlation magnitude is higher for those firms that suffer more from information asymmetries plaguing capital market (e.g. young and small firms). ${ }^{7}$

Regarding the drivers of growth, a growing number of contributions has robustly highlighted the central role of technological learning, innovation and diffusion carried out by business firms (see Dosi, Freeman, and Fabiani (1994) for a critical overview; more detailed discussions are in Rosenberg (1982, 1994), Freeman (1982) and Dosi (1988)).

The idea that aggregate growth can be traced back to business history finds quantitative roots in a series of robust stylized facts put forth by the literature on the microeconomics of innovation. In a synthesis:

SF7 Firms are the main locus where technological accumulation takes place. Technological learning - as well as its directions and rates - is carried out by firms in ways which are strongly shaped by: (a) firm-specific abilities; (b) richness of perceived unexploited opportunities. As a consequence, technological learning and accumulation tends to be mostly local: technical advances typically occur in a neighborhood of currently-mastered technologies. This cumulative learning pattern is 'punctuated' by major, low-probability advances which generate jumps in the technological space (i.e. changes in the technological paradigms).

SF8 Innovations take time to diffuse. Technological diffusion is slowed down by information asymmetries and, even more important, by the fact that firms require time to learn how to master new technologies and develop new skills.

SF9 Most innovations are industry-specific. Therefore, the overall pattern of business fluctuations cannot be fully explained by economy-wide innovative shocks.

In turn, the foregoing regularities concerning innovation and technological diffusion map onto the intersectoral patterns of realized performances and productivities. 
Extensive studies on longitudinal micro-level data sets - ranging from the seminal work of Nelson (1981) to the survey in Bartelsman and Doms (2000) - confirm that productivity dynamics is characterized by a few robust regularities, namely:

SF10 Productivity dispersion among firms is considerably large.

SF11 Inter-firm productivity differentials are quite persistent over time.

Moreover, heterogeneity concerns firm size distributions, both among firms belonging to the same industrial sector and across different industrial sectors (see, among a vast literature, and Bottazzi and Secchi $(2003 \mathrm{~b}, \mathrm{a})$ ).

SF12 Firm size distributions tend to be considerably right skewed, with upper-tails made of few large firms. These patterns vary significantly across different sectors.

As discussed at more length in e.g. Bottazzi, Cefis, and Dosi (2002), the foregoing regularity obviously supports the view that real-world markets strongly depart from perfect competition. Moreover, a growing evidence highlights microeconomic processes of growth entailing some underlying correlation structure and lumpiness. More precisely:

SF13 Firm growth-rate distributions are not Gaussian and can be well proxied by fat-tailed, tent-shaped densities.

According to $S F 13$, firm growth patterns tend to display relatively frequent 'big' - negative or positive - growth events.

In the model presented below, we take explicitly on board micro-regularities pertaining to firm investment and innovating behaviors $(S F 5-9)$ in the way we design the agents populating our economy, with the aim of building a model that, at the same time, is able to replicate and explain the stylized facts concerning the business cycle $(S F 1-4)$ on the basis of micro-dynamics patterns which replicate the statistical regularities displayed by the evolution of firm productivity, size and growth over time $(S F 10-13)$.

\section{Theoretical Roots and Antecedents}

We have already mentioned that the model which follows belongs to the evolutionary family. The seminal reference here is Nelson and Winter (1982). The work shows, among other things, the straightforward possibility of generating patterns of macroeconomic growth akin those observed in reality, on the grounds of a microeconomic structure made of heterogeneous agents that continuously try to innovate and imitate new techniques of production. There, however, any 'Keynesian' demand propagation effect is censored by construction, and so it is in many other models of evolutionary inspiration. ${ }^{8}$

The first attempts to explore the properties of evolutionary models with 'Keynesian' demand propagation effects can be found in Chiaromonte and Dosi 
(1993) and in the simpler but multi-economy framework studied in Dosi, Fabiani, Aversi, and Meacci (1994). In the former, one describes a two-sector economy with machine-embodied innovations, imperfect competition and two fundamental feedbacks running from investment to wages to aggregate demand (the 'multiplier'), and, the other way round, from aggregate demand to investment (the 'accelerator').

The present model refines upon this early templates and, for the first time, analyzes the fine statistical properties of the ensuing dynamics. Moreover, the model below tries to explicitly capture in its behavioral assumptions some of the micro regularities mentioned above.

Consider, for instance, investment lumpiness (cf. SF5). It is well-known that the latter can be in principle interpreted as the outcome of some optimizing behavior of a perfectly-rational firm. This is indeed what the so-called (S,s) investment models do. ${ }^{9}$ In that framework, firms face the problem of choosing the level of capital maximizing their flow of profits. If their desired capital is larger than the actual one, firms want to invest as long as they are able to recover capital adjustment costs. However, if the latter present some non-convexities, firms will invest up to some optimal target level (S) only if their capital imbalance is lower than a given optimal trigger threshold (s). Therefore, investment lumpiness straightforwardly derives from non-convexity of adjustment costs.

Notwithstanding the awareness that investment lumpiness may have significant consequences at the macro level, almost no attempts have been made to embed the observed microeconomic investment behavior into a business cycle model. ${ }^{10}$ More specifically, a surprisingly little attention has been paid so far to the interpretation of the stylized facts concerning the business cycle discussed above on the basis of the microeconomic evidence on firm investment behavior (cf. $S F 5$ and $S F 6$ ).

In this paper, we take a preliminary step in this direction. In our model, investment can be either employed to increase the capital stock or to replace existing capital goods. Consumption-good firms plan their expansion investment according to a $(\mathrm{S}, \mathrm{s})$ pattern. However, we depart from the standard lumpy investment literature in modeling firms as boundedly-rational agents. In particular, we assume that firms employ routinized behavioral investment rules instead of fully-rational, profitmaximizing behaviors cum non-convex adjustment costs (on routinized behaviors, see - within an enormous literature - Nelson and Winter (1982), Dosi (1988), Cyert and March (1989) and, much earlier, Katona and Morgan (1952)).

We interpret the target and trigger levels of an (S,s)-type of investment behavior in terms of a routinized investment rule, rather than as the outcome of some optimization procedure. Indeed, firms operating in 'evolutionary environments' (Dosi, Marengo, and Fagiolo, 2005) typically face strong uncertainty and cannot attach any probability measure to future outcomes (more on that in Dosi and Egidi (1991)). Hence, the adoption of a $(\mathrm{S}, \mathrm{s})$ rule fulfills the goals of a prudent, risk-averse, firm which is not able to fully anticipate its future level of demand and forms its expectations in an adaptive fashion. Firms will then decide to expand their stock of capital only if they expect a significant demand growth. As a result, they will invest 
to reach their target level of capital only if the fulfillment of their expected demand requires a capital stock at least equal to their trigger level.

Similarly to what happens for expansion investment, firms employ routinized behaviors to decide their replacement investment. ${ }^{11}$ In particular, we introduce heterogenous capital goods and we assume that firms implement their replacement policy through a payback-period routine. In this way, technical change and capital good prices enter in the replacement decisions of consumption-good firms.

Finally, the financial structure of the firm does affect in our model its investment policies (cf. SF6). Indeed, the presence of financial constraints implies that firms pay a premium if they rely on external sources of funds (i.e. credit). Therefore, the financial structure of firms might not be neutral: firms may turn to external credit when their stock of liquid assets is not enough to fully finance their investment plans.

\section{The Model}

We model an economy populated by $F$ firms and $L$ workers/consumers. Firms are split in two industries: there are $F_{1}$ consumption-good firms (labeled by $j$ in what follows) and $F_{2}$ machine-tool firms (labeled by $i$ ). Of course, $F=F_{1}+$ $F_{2}$. Consumption-good firms invest in machine-tools and produce a homogeneous product for consumers. Machine-tool firms produce heterogenous capital goods and perform R\&D. Workers inelastically sell labor to firms in both sectors and fully consume the income they receive. Investment choices of consumption-good firms determine the level of income, consumption and employment in the economy.

In the next subsection, we shall firstly describe in a telegraphic way the dynamics of events in a representative time-period. Next, we shall provide a more detailed account of each event separately.

\subsection{THE DYNAMICS OF MICROECONOMIC DECISIONS}

In any discrete time period $t=1,2, \ldots$, the timeline of events runs as follows: ${ }^{12}$

1. Consumption-good firms take their production and investment decisions. According to their expected demand, firms fix their desired production and, if necessary, invest to expand their capital stock. A payback period rule is employed to set replacement investment. Credit-rationed firms finance their investment, first with their stock of liquid assets, and next, if necessary, with debt.

2. Capital-good market opens. Market shares and their changes depend on the 'competitiveness' of each machine-producing firm.

3. Consumption-good market opens. Consumption-good production takes place. Unemployment rates and monetary wage emerge as the collective outcome of micro-decisions. The size of the consumption-good demand depends on the number of workers employed by firms. Consumption-good firms facing imperfectly informed consumers receive a fraction of the total demand as a function of their price competitiveness.

4. Exit, technical change and entry. Firms facing negative net liquid assets and/or a 
non-positive market-share exit and they are replaced by new firms. Capital-good firms stochastically search for new machines.

Finally, total consumption, investment, change in inventories, and total product are obtained by aggregating individual time- $t$ quantities.

\subsection{PRODUCTION AND INVESTMENT: THE CONSUMPTION-GOOD SECTOR}

Each consumption-good firm $j=1,2, \ldots, F_{1}$ produces a homogenous good using machines and labor under constant returns to scale. Planned output depends on adaptive demand expectations of the form:

$$
D_{j}^{e}(t)=f\left(D_{j}(t-1), Y(t-1), D_{j}(t-2), Y(t-2) \ldots\right),
$$

where $D_{j}(t-1)$ is the demand of firm $j$ at time $t-1$ and $Y(t-1)$ is the level of aggregate output at time $t-1$. In fact, we explore different extrapolative rules based on both firm-specific past demand and aggregate market signal (see section 4.3, below for details).

According to the expected demand and the inventories $\left(N_{j}\right)$ inherited from the previous period, firms fix their desired level of production $\left(Q_{j}^{d}\right)$ :

$$
Q_{j}^{d}(t)=D_{j}^{e}(t)-N_{j}(t-1) .
$$

The stock of capital determines the maximum level of production achievable by each firm. Hence, given the desired level of production, firms compute the desired stock of capital as:

$$
K_{j}^{d}(t)=\frac{Q_{j}^{d}(t)}{u^{d}},
$$

where $u^{d}$ is the desired level of capacity utilization.

Consumption-good firms decide whether to expand ${ }^{13}$ their stock of capital following an (S,s) model. They compute their trigger $\left(K_{j}^{\text {trig }}\right)$ level of capital as follows:

$$
K_{j}^{\text {trig }}=K_{j}(t)(1+\alpha)
$$

with $0<\alpha<1$. Firms then plan to increase their capital stock only if the desired capital stock is higher than the trigger one:

$$
E I_{j}(t)=\left\{\begin{array}{cl}
0 & \text { if } K_{j}^{d}(t)<K_{j}^{\text {trig }}(t) \\
K_{j}^{t r i g}(t)-K_{j}(t) & \text { if } K_{j}^{d}(t) \geq K_{j}^{\text {trig }}(t),
\end{array}\right.
$$

where $E I_{j}(t)$ is the expansion investment. 
Such a routine-based behavior as already mentioned is amply justified by the complexity of the environment in which the firms are nested, characterized by strong market and technological uncertainty.

The stock of capital of each consumption-good firm is heterogeneous, since it is composed of various vintages of machines which differ in terms of productivity. Machines are measured in terms of their production capacity, which is normalized to one. They are identified by a labor productivity coefficient $A_{i, \tau}$, where $i$ denotes their producer and $\tau$ their generation (technical change takes place through the creation of new generation of machines. See section 4.7 below for details). Let $\Xi_{j}(t)$ be the set of all types of machines belonging to firm $j$ at time $t$. Firm $j$ 's capital stock is defined as:

$$
K_{j}(t)=\sum_{A_{i \tau} \in \Xi_{j}(\tau)} g_{j}\left(A_{i, \tau}, t\right),
$$

where $g_{j}\left(A_{i, \tau}, t\right)$ is the absolute frequency of machine $A_{i, \tau}$. Given the nominal wage $\mathrm{w}(\mathrm{t})$, the unit labor cost of each machine is computed as:

$$
c\left(A_{i, \tau}, t\right)=\frac{w(t)}{A_{i, \tau}}
$$

Scrapping policies follow a payback-period routine. The replacement of an incumbent machine depends on its degree of 'technological' obsolescence and on the market price of new capital goods. More formally, firm $j$ will scrap machines $A_{i, \tau} \in \Xi_{j}(t)$ if they satisfy:

$$
R S_{j}(t)=\left\{A_{i, \tau} \in \Xi_{j}(t): \frac{p^{*}(t)}{c\left(A_{i, \tau}, t\right)-c^{*}(t)} \leq b\right\},
$$

where $p^{*}$ and $c^{*}$ are, respectively, the average market price and unit labor cost of new machines, and $\mathrm{b}$ is a strictly positive payback-period parameter. Hence, the replacement investment $\left(R I_{j}\right)$ of firm $j$ will be equal to:

$$
R I_{j}(t)=\sum_{A_{i, \tau} \in R S_{j}(t)} g_{j}\left(A_{i, \tau}, t\right)
$$

i.e. each consumption-good firm computes its replacement investment $\left(R I_{j}\right)$ by 'adding' the number of machines that satisfy eq. (5). The level of investment $\left(I_{j}\right)$ is the sum of expansion and replacement investment. Summing up the actual investment of all consumption-good firms, we get aggregate investment $(I)$.

Firms must bear production costs before selling their output. Hence, they must finance production as well as investment. In tune with the spirit of the evolutionary perspective, but also of many New Keynesian models, we assume imperfect capital market with credit rationing. Firms use first their stock of liquid assets $\left(N W_{j}\right)$ 
to finance production. If internal funds are not sufficient, firms borrow up to a maximum debt/sales ratio $\Omega_{\max }$, paying an interest rate $r$. More precisely, production is rationed if:

$$
c_{j}(t) Q_{J}(t)+\operatorname{Deb}_{j}(t-1)>S_{j}(t-1) \Omega_{\max }+N W_{j}(t-1),
$$

where $c_{j}$ denotes unit cost of production, $S_{j}$ is total sales and $D e b_{j}$ is the stock of debt. If production is not rationed, firms finance investment relying on their residual stock of liquid assets and, if necessary, on their residual debt availability. If firms cannot afford to fully finance investment, they privilege expansion investment over replacement investment.

When consumption-good firms receive new machines, they update their average productivity $\left(\pi_{j}\right)$ and their unit cost of production $\left(c_{j}\right)$. Average productivity reads:

$$
\pi_{j}(t)=\sum_{A_{i, \tau} \in \Xi_{j}(t)} A_{i, \tau} \frac{g_{j}\left(A_{i, \tau}, t\right)}{K_{j}(t)},
$$

while unit cost of production will be given by:

$$
c_{j}(t)=\frac{w(t)}{\pi_{j}(t)}
$$

Firms fix the price as a mark-up on their unit cost of production:

$$
p_{j}(t)=(1+\mu) c_{j}(t)
$$

with $\mu>0$. Given their average productivity and their production, consumptiongood firms determine their labor demand $\left(L_{j}^{D}\right)$ :

$$
L_{j}^{D}(t)=\frac{Q_{j}(t)}{\pi_{j}(t)}
$$

Firms compute their profits $\left(\Pi_{j}\right)$ as:

$$
\Pi_{j}(t)=p_{j}(t) S_{j}(t)-c_{j}(t) Q_{j}(t)-r D e b_{j}(t) .
$$

The variation of the stock of liquid asset of consumption-good firms depends on their profits as well as on their investment choices:

$$
N W_{j}(t)=N W_{j}(t-1)+\Pi_{j}(t)-c I_{j},
$$

where $c I_{j}$ is the amount of internal funds employed by firm $j$ to finance investment. 


\subsection{DEMAND EXPECTATIONS}

As mentioned, we experiment with diverse forms of adaptive expectations characterized by somewhat different computing abilities and extrapolating routines. In the simplest case, we assume that consumption-good firms are endowed with perfectly myopic expectations:

$$
D_{j}^{e}(t)=D_{j}(t-1) .
$$

Second, we allow for some extrapolative rule and a longer memory (call it the autoregressive expectation case):

$$
D_{j}^{e}(t)=\beta_{1} D_{j}(t-1)+\beta_{2} D_{j}(t-2)+\beta_{3} D_{j}(t-3)+\beta_{4} D_{j}(t-4),
$$

with $0 \leq \beta_{1,2,3,4}<1$.

Third, we model firms considering both the level and the variation of their past demand $\left(\Delta D_{j}(t-1)\right)$. In this case firms have accelerative expectations:

$$
D_{j}^{e}(t)=\left[1+\beta_{5} \Delta D_{j}(t-1)\right] D_{j}(t-1),
$$

with $0<\beta_{5}<1$.

Fourth, we allow firms to learn also from their past forecast and past mistakes. Let us call it the adaptive expectation case:

$$
D_{j}^{e}(t)=D_{j}^{e}(t-1)+\beta_{6}\left[D_{j}(t-1)-D_{j}^{e}(t-1)\right],
$$

with $\beta_{6}>0$.

Finally, in the fifth case firms consider also the dynamics of the whole economy. This is the micro-macro expectation case:

$$
D_{j}^{e}(t)=\left[1+\beta_{7} \Delta D_{j}(t-1)+\beta_{8} \Delta Y(t-1)\right] D_{j}(t-1),
$$

where $Y$ denotes the aggregate output and $0<\beta_{7,8}<1$.

\subsection{MACHINE PRODUCTION}

In the previous sections we have modeled the formation of demand for capital goods. Let us now describe how the machine producing sector works.

Each machine-tool firm $i=1,2, \ldots, F_{2}$ sells its latest generation of products characterized by labor productivity coefficient $A_{i, \tau}$, with $\tau=1,2, \ldots$. The production process employs labor only under constant returns to scale. The unit cost of production is specific to the firm and to the produced vintage:

$$
c_{i}(t)=\frac{w(t)}{A_{i, \tau}} .
$$


Firms set the price according to a mark-up $(\mu)$ rule:

$$
p_{i}(t)=(1+\mu) c_{i}(t)
$$

where $\mu \geq 0$.

As it happens in the consumption-good industry, machine-tool firms bear the costs of production before receiving the revenues. They finance production with their stock of liquid assets $\left(N W_{i}\right)$ and if necessary with external funds. Once the level of production is determined, firms can hire workers according to:

$$
L_{i}^{D}(t)=\frac{Q_{i}(t)}{A_{i, \tau}},
$$

where $L_{i}^{D}$ is the labor demand of firm $i$.

Firm $i$ 's profits $\left(\Pi_{i}\right)$ will be then given by:

$$
\Pi_{i}(t)=\left[p_{i}(t)-c_{i}(t)\right] Q_{i}(t)-r \operatorname{Deb}_{i}(t)
$$

The stock of liquid assets changes according to:

$$
N W_{i}(t)=N W_{i}(t-1)+\Pi_{i}(t) .
$$

\subsection{THE CONSUMPTION-GOOD MARKET}

In this and in the next section we present how the markets for producer- and consumer goods work. We first consider the consumption-good market.

Since consumption-good firms take their production decisions according to their demand expectations, they can obviously make mistakes which are revealed by variations in inventories. If in the previous period they produced too much $\left(Q_{j}(t-1)>D_{j}(t-1)\right)$, they accumulate stocks. On the contrary, if they were not able to fully satisfy their past demand, their 'competitiveness' $\left(E_{j}\right)$ at time $t$ is reduced:

$$
E_{j}(t)=-\omega_{1} p_{j}(t)-\omega_{2} l_{j}(t)
$$

where $l_{j}$ is the level of unfilled demand inherited from the previous period and $\omega_{1,2}$ are non-negative parameters. The average sectorial competitiveness $\left(\bar{E}^{j}\right)$ is obtained by weighting the competitiveness of each firm with its past market share $\left(f_{j}(t-1)\right)$ :

$$
\bar{E}^{j}(t)=\sum_{j=1}^{F_{1}} E_{j}(t) f_{j}(t-1) .
$$


Under condition of imperfect information, consumers take time to imperfectly adjust to relative consumption-good prices. Thus, market shares evolve according to a replicator dynamics. More specifically, the market share of each firm will grow (shrink) if its competitiveness is above (below) the industry-average competitiveness:

$$
f_{j}(t)=f_{j}(t-1)\left(1+\chi_{1} \frac{E_{j}(t)-\bar{E}^{j}(t)}{\bar{E}^{j}(t)}\right),
$$

with $\chi_{1} \geq 0 .{ }^{14}$

Aggregate consumption (cf. section 4.8) shapes the demand-side of the market and it is allocated to consumption-good firms according to their market share:

$$
D_{j}(t)=C(t) f_{j}(t)
$$

\subsection{THE CAPITAL-GOOD MARKET}

Let us now turn to the capital-good market. Capital-good firms produce on demand. Hence, since they are always able to fully satisfy their demand, their 'competitiveness' depends on the price they charge and on the productivity of the machines they offer:

$$
E_{i}(t)=-\omega_{3} p_{i}(t)+\omega_{4} A_{i, \tau},
$$

where $\omega_{3}$ and $\omega_{4}$ are non-negative parameters. As in the consumption-good industry, average sectoral competitiveness $\left(\bar{E}^{i}\right)$ and market shares $\left(f_{i}\right)$ read:

$$
\begin{aligned}
\bar{E}^{i}(t) & =\sum_{i=1}^{F_{2}} E_{i}(t) f_{i}(t-1) \\
f_{i}(t) & =f_{i}(t-1)\left(1+\chi_{2} \frac{E_{i}(t)-\bar{E}^{i}(t)}{\bar{E}^{i}(t)}\right),
\end{aligned}
$$

with $\chi_{2} \geq 0$. Also in this case, since the market is characterized by imperfect information, there is inertia in the adjustment process of the market shares.

The demand side of the capital-good market depends on the investment choices of consumption-good firms. More specifically, final-good firm orders determine the size of the investment 'cake', whose slices $\left(D_{i}\right)$ are allocated according to the market share of each producers:

$$
D_{i}(t)=I(t) f_{i}(t)
$$




\subsection{ENTRY, EXIT, AND TECHNICAL CHANGE}

At the end of every period, firms with zero market shares and/or negative net assets die and are replaced by new firms. Hence, the number of firms in both sectors remain constant across time. In order not to bias the overall dynamics, we start by assuming that each entrant is a random copy of a survived firm (see, however, Section 5 for a discussion on more empirically-plausible entry rules).

As mentioned, our economy is fuelled by a never-ending process of technical change. At the end of each period, machine-tool firms try to develop the next generation of their product (i.e. discovering machines with a higher labor productivity coefficient). The result of their efforts is strongly uncertain: firms develop a prototype whose labor productivity $\left(A_{i, \text { new }}\right)$ may be higher or lower than the one of the currently manufactured machine. More formally, we let:

$$
A_{i, \text { new }}=A_{i, t}(1+\epsilon)
$$

where $\epsilon \sim U\left[\iota_{1}, \iota_{2}\right]$. We also posit that firm $i$ will release the next generation machine only if the latter entails a labor productivity improvement (i.e. $A_{i, \text { new }}>A_{i, \tau}$ ). Finally, if the firm decides to produce the new machine, the index $\tau$ is accordingly incremented by one unit.

\subsection{MACRO DYNAMICS}

The dynamics generated at the micro-level by individual decisions and interaction mechanisms induces, at the macroeconomic level, a stochastic dynamics for all aggregate variables of interest (e.g. output, investment, consumption, unemployment, etc.).

Labor market is not cleared by real wage movements. As a consequence, involuntary unemployment may arise. The aggregate supply of labor is exogenous, inelastic and grows at a constant rate $(\eta)$ :

$$
L(t)=L(t-1)(1+\eta)
$$

The aggregate demand of labor is the sum of machine- and consumption-good firms' labor demands:

$$
L^{D}(t)=\sum_{j=1}^{F_{1}} L_{j}^{D}+\sum_{i=1}^{F_{2}} L_{i}^{D}(t) .
$$

Hence, aggregate employment (Emp) reads:

$$
\operatorname{Emp}(t)=\min \left(L^{D}(t), L(t)\right)
$$


The wage rate is determined by both institutional and market factors, with both indexation mechanisms upon consumption prices and average productivity, on the one hand, and, adjustments to unemployment rates, on the others:

$$
\begin{aligned}
w(t)= & w(t-1)+\left(1+\psi_{1} \frac{c p i(t)-c p i(t-1)}{c p i(t-1)}\right. \\
& \left.+\psi_{2} \frac{\bar{A}(t)-\bar{A}(t-1)}{\bar{A}(t-1)}+\psi_{3} \frac{U(t)-U(t-1)}{U(t-1)}\right),
\end{aligned}
$$

where $c p i$ is the consumer price index, $\bar{A}$ is average labor productivity and $U$ is the unemployment rate. The system parameters $\psi_{1,2,3}$ allow one to characterize various institutional regimes for the labor market.

In addition to the industries producing consumption goods and machines - call them the tradable sector of the economy - it is reasonable to assume a parallel source of aggregate demand associated with a non-market sector - including of course in its empirical counterpart government services. In the model, its admittedly black-boxed representation is through a contribution to aggregate consumption proportional to the whole labor force and the aggregate wage bill:

$$
C(t)=w(t) \operatorname{Emp}(t)+\varphi w(t) L,
$$

with $0<\varphi<1$.

Our model straightforwardly belongs to the evolutionary/ACE class. Since in general, analytical, closed-form, solutions can hardly be obtained, one must resort to computer simulations to analyze the properties of the (stochastic) processes governing the coevolution of micro and macro variables. ${ }^{15}$

To do so, one should in principle address an extensive Monte Carlo analysis in order to understand how the statistics of interests change together with initial conditions and system parameters. Notice, in any case, that in our model the only stochastic component affecting the underlying dynamics is given by technological improvements in machine efficiencies. In fact, sensitivity exercises show that the across-simulation stochastic variability is quite low and no chaotic pattern is detected. Hence, we can confidently present below results concerning averages over a limited number of replications (typically $M=50$ ) as a robust proxy for the behavior of all time-series of interest.

\section{Simulation Results}

How does the model fare in terms of its ability to account for the empirical regularities presented in sections 2.1 and 2.2? Here we shall present in detail the simulation results under the 'perfectly myopic' scenario and compare them with the results 


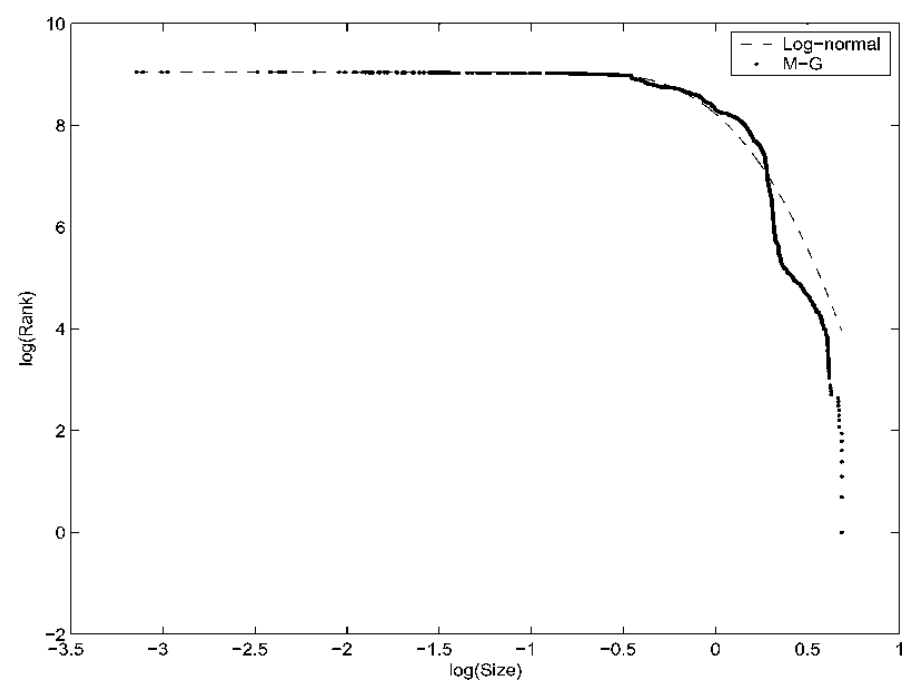

Figure 1. Pooled (Year-Standardized) Sales Distributions. Log Rank vs. Log Size Plots. M-G: Model-Generated Distribution. Perfectly Myopic Expectation Regime.

obtained in the other expectations regimes (see Section 4.3). The values of parameters and initial conditions are spelled out in Appendix A.

First, let us look at the outcomes of the model when technical change is turned off. In this case, the model behaves like the Solow (1956) growth model: the economy is in steady state and the output growth rate coincides with the labor supply growth rate. Of course, if we keep the population constant, the output growth rate falls to zero.

Second, as soon as one turns on technical change, self-sustaining patterns of growth do emerge (see Fig. 3) and the average output growth rate (cf. eq. 22) becomes significantly higher than the population growth rate. The analysis of investment components also shows that the behavior of aggregate investment is the result of huge changes in both expansion and replacement investment (see Fig. 4).

Third, if we separate the business cycle frequencies of the series by applying a bandpass filter, ${ }^{16}$ we observe the typical 'roller coaster' shape that characterizes real data (see Fig. 5 and section 2.1 above).

Fourth, our simulated series of aggregate investment appear to be more volatile than output, and expansion investment fluctuates more wildly than replacement investment (cf. Fig. 6).

Fifth, aggregate investment and consumption seem to display a procyclical behavior. Interestingly, the foregoing qualitative properties do not significantly change if we let consumption-good firms follow more sophisticated expectation formation rules (cf. Section 4.3). As we show in much more detail in Dosi, Fagiolo, and Roventini (2005), output and investment appear to be somewhat less volatile if 
AN EVOLUTIONARY MODEL OF ENDOGENOUS BUSINESS CYCLES

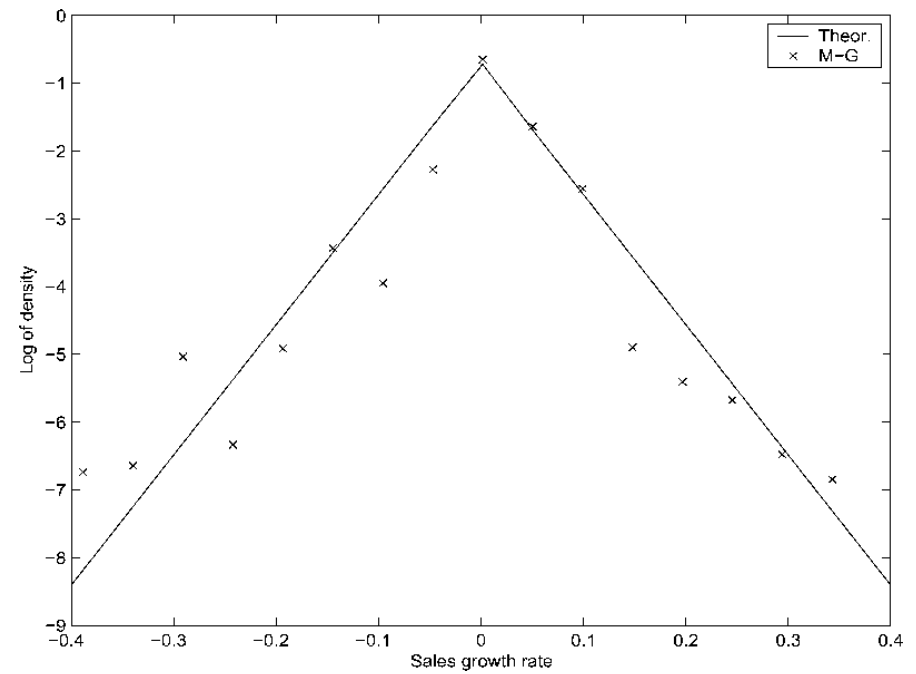

Figure 2. Pooled (Year-Standardized) Firm Growth Rates. Binned Densities of Simulated Growth Rates vs. Laplace Fit. M-G: Model-Generated Growth Rates. Perfectly Myopic Expectation Regime.

firms are now endowed with autoregressive expectations (cf. eq. 8). Moreover, if one assumes autoregressive or accelerative expectation set-ups (cf. eq. 9), expansion investment appears to be less lumpy (a more detailed comparison of alternative expectation regimes is performed below).

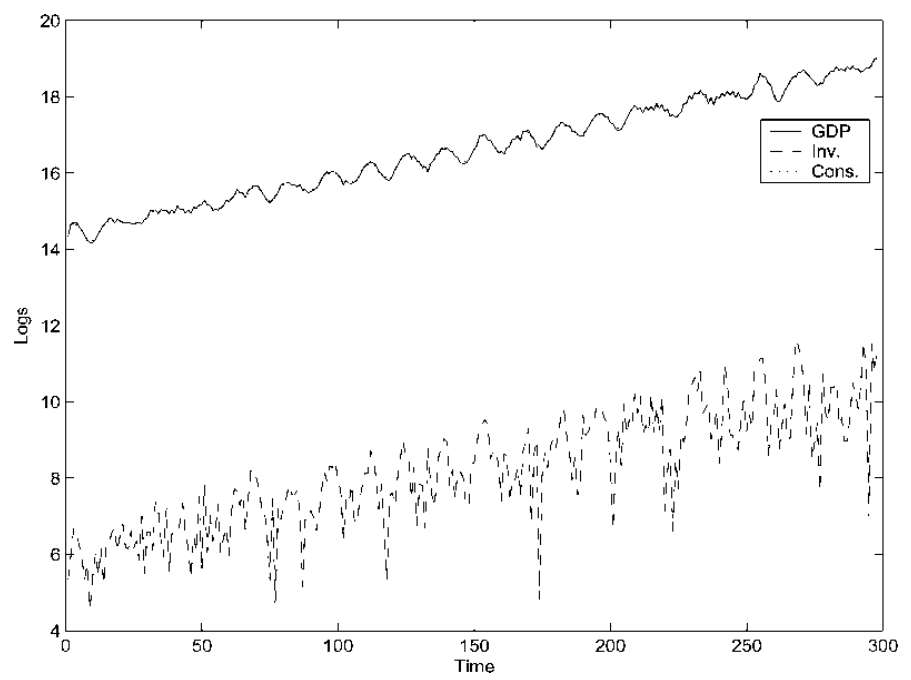

Figure 3. Level of Output, Investment and Consumption. Perfectly Myopic Expectation Regime. 


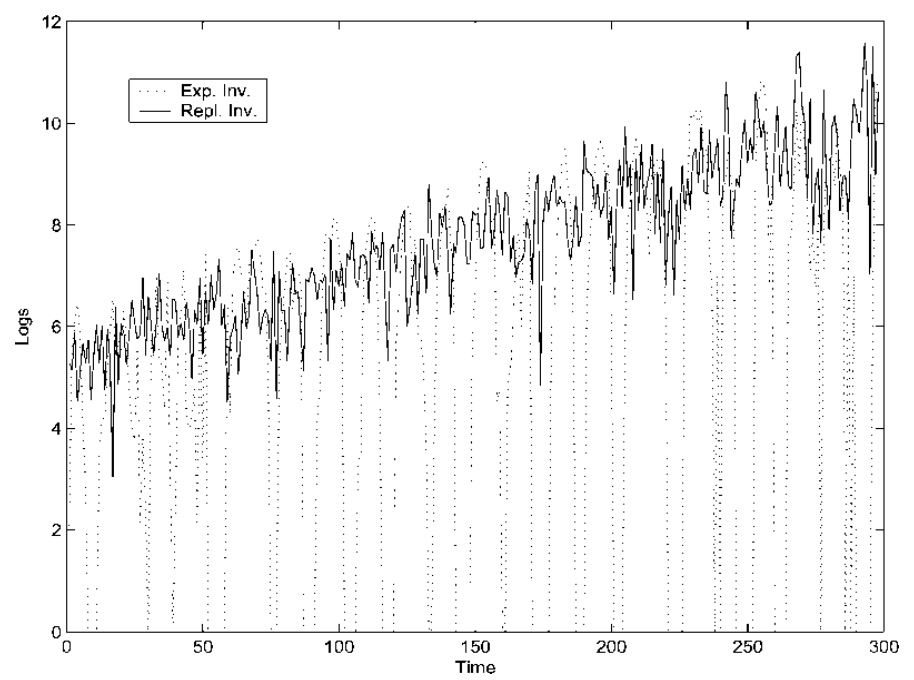

Figure 4. Expansion and Replacement Investment. Perfectly Myopic Expectation Regime.

An important advantage of the model as compared with its 'representative agent' rivals is that it also generates a microeconomic landscape consistent with the micro 'stylized facts' mentioned in section 2.2. So, for example, the skewed firm size distributions which emerge in the simulations clearly depart from the log-normal benchmark as happens in reality (cf. the rank-size plot in Figure 1). ${ }^{17}$ Moreover, in tune with the empirical evidence, pooled growth rates of our simulated firms exhibit

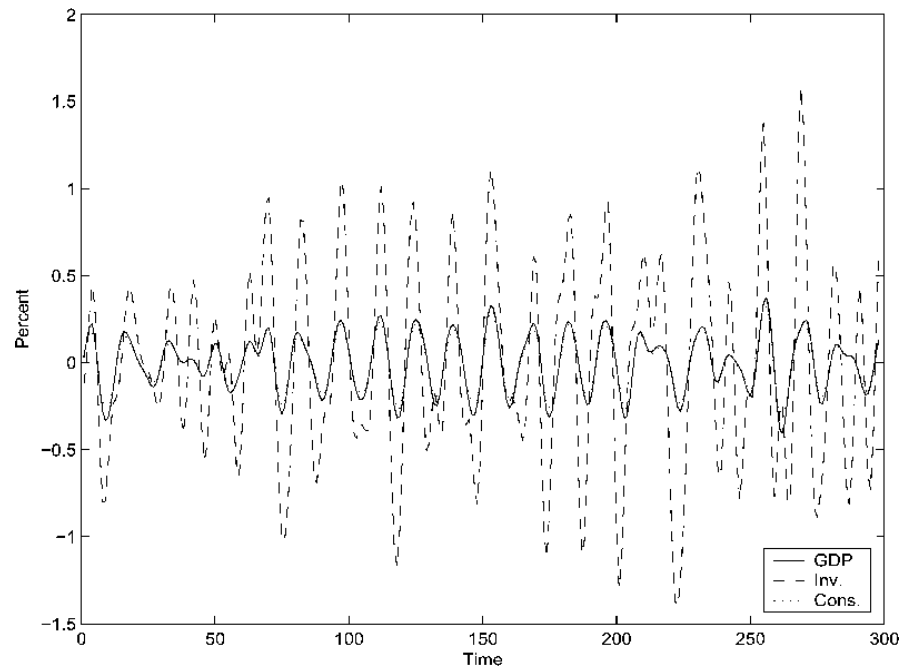

Figure 5. Bandpass-Filtered Output, Investment and Consumption. Perfectly Myopic Expectation Regime. 


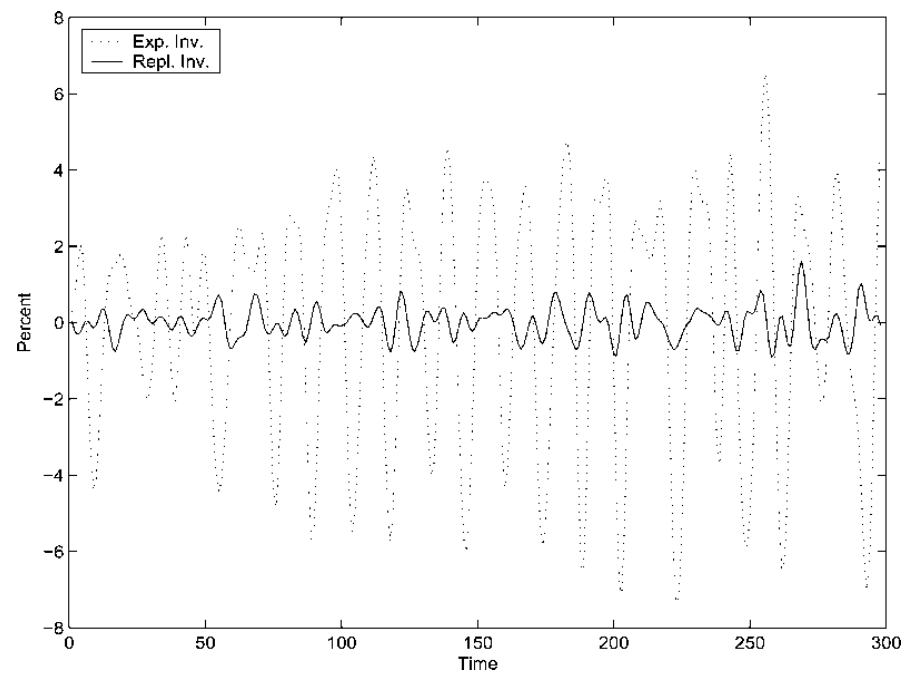

Figure 6. Bandpass-Filtered Expansion and Replacement Investment. Perfectly Myopic Expectation Regime.

the typical 'tent-shaped' patterns, characterized by tails fatter than the Gaussian benchmark (cf. Fig. 2). What is more, if one fits simulated distributions with the family of Subbotin densities, the estimated shape-parameter turns out to be very close to the one obtained in empirical studies. ${ }^{18}$

Let us now turn to a more detailed study of our simulated time-series. More specifically, let us address the issue whether simulated series of aggregate output growth, investment, consumption, etc. display statistical properties similar to the empirically observed ones (as summarized in $S F 1-4$ ).

We begin by focusing on the average growth rate (AGR) of the economy:

$$
A G R_{T}=\frac{\log Y(T)-\log Y(0)}{T+1}
$$

where $Y$ denotes aggregate output and compute Dickey-Fuller (DF) tests on output, consumption and investment in order to detect the presence of unit roots in the series. All results refer to averages computed across $M=50$ independent simulations.

The average growth rate of output, consumption and investment are strictly positive $(\approx 1.5 \%$, see top panel of Table II) and DF tests suggest that output, consumption, and investment are non-stationary.

We then detrend the time series obtained from simulations with a bandpass filter $(6,32,12)$ and we compute standard deviations and cross-correlations between output and the other series. ${ }^{19}$ Relative standard deviation levels suggest that the model is able to match $S F 1$ (i.e. investment is considerably more volatile than output) and $S F 2$ (i.e. consumption is less volatile than output). The volatility of 
G. DOSI, G. FAGIOLO AND A. ROVENTINI

Table II. Output, Investment and Consumption Statistics under Alternative Demand Expectations Regimes.

\begin{tabular}{lccc}
\hline & GDP & Consumption & Investment \\
\hline Perfectly Myopic Expectations & & & \\
Avg. growth rate (\%) & $1.50 \%$ & $1.51 \%$ & $1.54 \%$ \\
Dickey-Fuller test (logs) & 2.8715 & 3.9986 & -0.9186 \\
Dickey-Fuller test (bpf 6,32,12) & $-4.8703^{*}$ & $-4.8040^{*}$ & $-5.6382^{*}$ \\
Std. Dev. (bpf 6,32,12) & 0.1931 & 0.1659 & 0.6089 \\
Rel. Std. Dev. (GDP) & 1 & 0.8590 & 3.1536 \\
Autoregressive Expectations & & & \\
Avg. growth rate (\%) & $1.54 \%$ & $1.53 \%$ & $1.58 \%$ \\
Dickey-Fuller test (logs) & 6.4372 & 9.4470 & -0.4309 \\
Dickey-Fuller test (bpf 6,32,12) & $-4.8703^{*}$ & $-4.8380^{*}$ & $-5.1365^{*}$ \\
Std. Dev. (bpf 6,32,12) & 0.0767 & 0.0672 & 0.3183 \\
Rel. Std. Dev. (GDP) & 1 & 0.8763 & 4.1482 \\
Accelerative Expectations & & & \\
Avg. growth rate (\%) & $1.52 \%$ & $1.50 \%$ & $1.66 \%$ \\
Dickey-Fuller test (logs) & 2.2160 & 3.6865 & -0.3357 \\
Dickey-Fuller test (bpf 6,32,12) & $-5.5105^{*}$ & $-5.5063^{*}$ & $-5.9885^{*}$ \\
Std. Dev. (bpf 6,32,12) & 0.1630 & 0.1379 & 0.4059 \\
Rel. Std. Dev. (GDP) & 1 & 0.8463 & 2.4909 \\
Adaptive Expectations & & & \\
Avg. growth rate (\%) & $1.56 \%$ & $1.56 \%$ & $1.73 \%$ \\
Dickey-Fuller test (logs) & 3.0319 & 4.1459 & -0.8462 \\
Dickey-Fuller test (bpf 6,32,12) & $-4.9501^{*}$ & $-4.8922^{*}$ & $-5.6906^{*}$ \\
Std. Dev. (bpf 6,32,12) & 0.1915 & 0.1646 & 0.6085 \\
Rel. Std. Dev. (GDP) & 1 & 0.8596 & 3.1775 \\
Micro-Macro Expectations & & & \\
Avg. growth rate (\%) & $1.44 \%$ & $1.45 \%$ & $0.53 \%$ \\
Dickey-Fuller test (logs) & 2.4223 & 3.1405 & -1.7463 \\
Dickey-Fuller test (bpf 6,32,12) & $-5.6499^{*}$ & $-5.5816^{*}$ & $-5.8515^{*}$ \\
Std. Dev. (bpf 6,32,12) & 0.2118 & 0.1792 & 0.7649 \\
Rel. Std. Dev. (GDP) & 1 & 0.8463 & 3.6123 \\
\hline Asterisks (*): Signictiva & & \\
\hline
\end{tabular}

Asterisks (*): Significative at $99 \%$ level.

aggregate investment is indeed 3 times larger than the output one, whereas the relative volatility of consumption is 0.86 .

As far as cross-correlations are concerned, consumption, investment and change in inventories all appear to satisfy $S F 3$ : they are procyclical and coincident variables (cf. top panel of Table III). Moreover, as Fig. 7 shows, our simulated crosscorrelation patterns are qualitatively similar to those obtained by Stock and Watson 


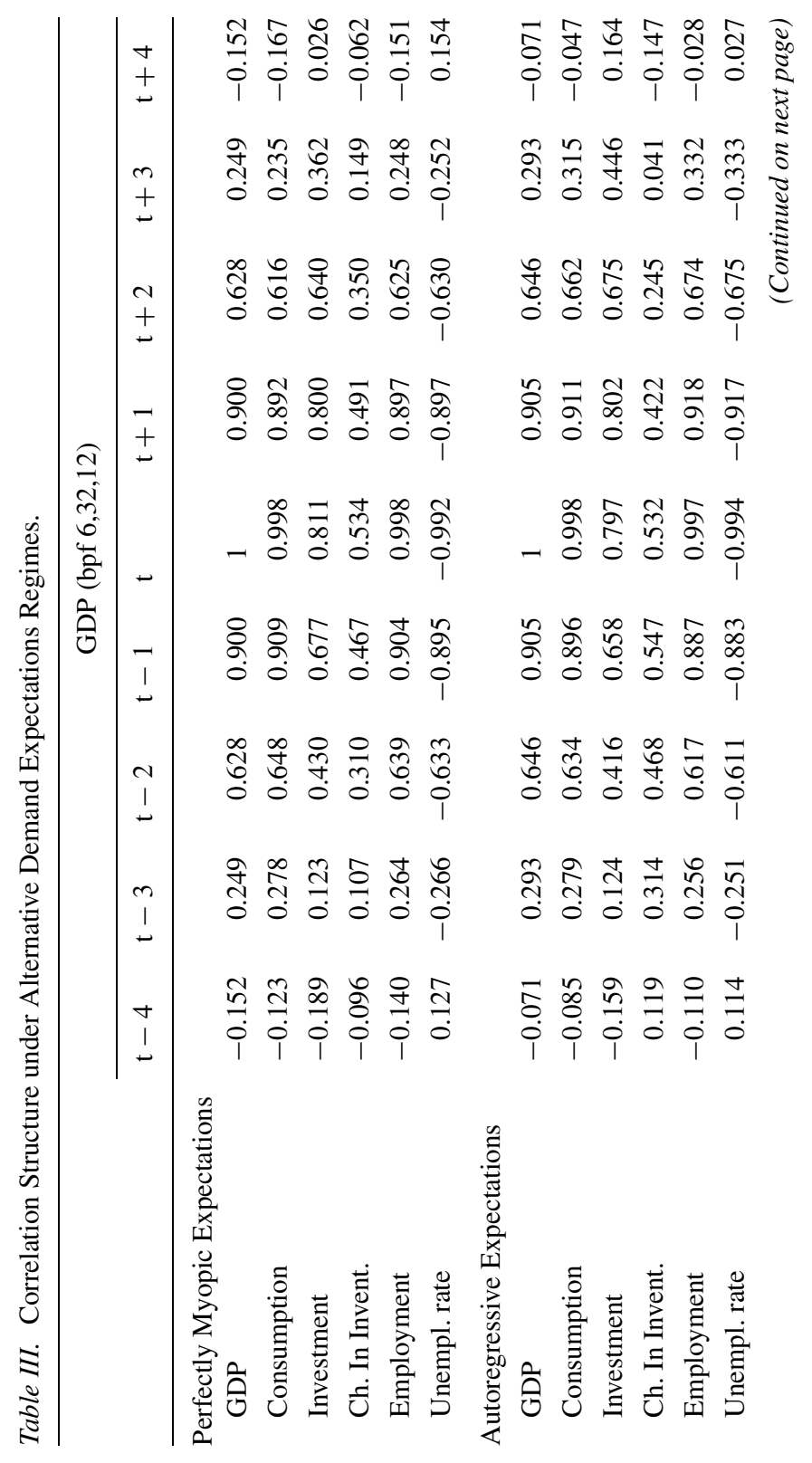



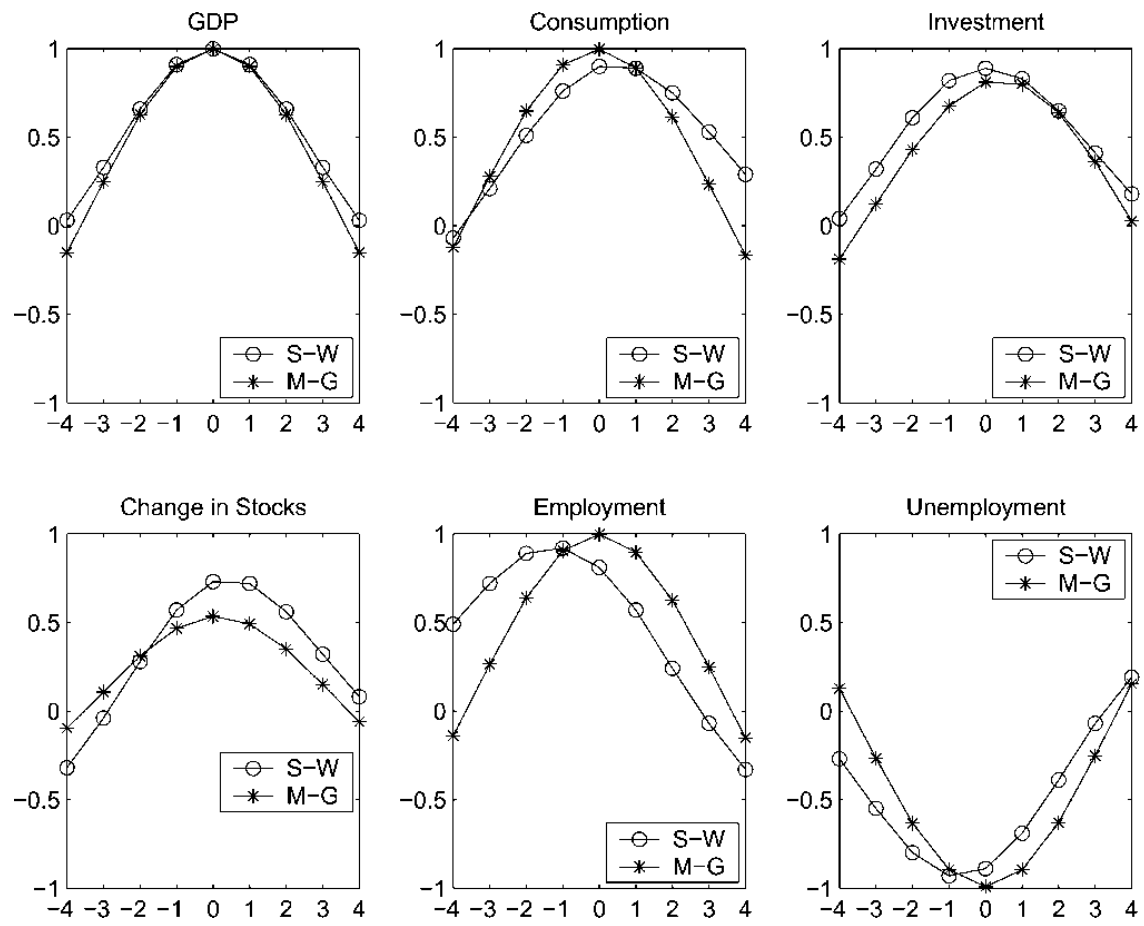

Figure 7. Model Generated (M-G) vs. Empirical Data (S-W: Stock and Watson, 1999) Crosscorrelations. Perfectly Myopic Expectation Regime.

(1999) on U.S. data. Notice that business cycle models (e.g. RBC models) usually attempt to match only contemporaneous correlations between GDP and other variables. On the contrary, our model is able to qualitatively replicate the entire cross-correlation structures (i.e. at different leads and lags).

In addition, employment turns out to be procyclical, while the unemployment rate is anticyclical $(S F 4)$, Yet, the two variables appear to be coincident. This result may stem from the complete lack of frictions that characterizes the labor market in our model. Indeed, since in every time period firms can hire and fire workers without limitations, production fluctuations pour out in the labor market with no lags.

If we move to the other expectation regimes, the ability of the model to replicate $S F 1-4$ does not significantly change. Investment relative standard deviation increases in the autoregressive expectation scenario (cf. 2nd panel of Table II from the top), whereas it becomes lower in the accelerative expectation regime (cf. Table II, 3rd panel), but, in any case, SF1 is always matched. According to crosscorrelations, SF3 is not completely satisfied only in the autoregressive expectation scenario. Investment becomes slightly leading and change in inventories turns to slightly lagging (see 2nd panel of Table III).

The model is also robust to different entry rules. Indeed, in line with the firm demography literature, we have modified the entry rule in order to have entrants 
Table IV. Robustness of Simulation Results to Alternative Entry Rules. $N W_{i n}$ : Stock of Liquid Assets of Entrant Firms (Perfectly Myopic Expectation Regime).

\begin{tabular}{|c|c|c|c|c|c|c|}
\hline \multirow{2}{*}{$\begin{array}{c}\text { Entry Rule } \\
N W_{i n} \geq \zeta \overline{N W_{k}}\end{array}$} & \multirow[b]{2}{*}{ Series } & \multirow{2}{*}{$\begin{array}{c}\text { Avg. } \\
\text { Gr. Rate }\end{array}$} & \multirow{2}{*}{$\begin{array}{c}\text { Std. Dev. } \\
\text { (bpf 6,32,12) }\end{array}$} & \multicolumn{3}{|c|}{ GDP (bpf 6,32,12) } \\
\hline & & & & $\mathrm{t}-1$ & $\mathrm{t}$ & $\mathrm{t}+1$ \\
\hline & GDP & $1.59 \%$ & 0.1719 & 0.8946 & 1 & 0.8946 \\
\hline \multirow[t]{3}{*}{$\zeta=1$} & Consumption & $1.57 \%$ & 0.1460 & 0.9053 & 0.9969 & 0.8825 \\
\hline & Investment & $1.75 \%$ & 0.5764 & 0.6216 & 0.7381 & 0.7207 \\
\hline & GDP & $1.53 \%$ & 0.1730 & 0.8949 & 1 & 0.8949 \\
\hline \multirow[t]{3}{*}{$\zeta=0.75$} & Consumption & $1.51 \%$ & 0.1468 & 0.9054 & 0.9970 & 0.8831 \\
\hline & Investment & $1.36 \%$ & 0.5992 & 0.6300 & 0.7322 & 0.7058 \\
\hline & GDP & $1.51 \%$ & 0.1784 & 0.8896 & 1 & 0.8896 \\
\hline \multirow[t]{2}{*}{$\zeta=0.5$} & Consumption & $1.50 \%$ & 0.1517 & 0.8995 & 0.9979 & 0.8802 \\
\hline & Investment & $1.50 \%$ & 0.5303 & 0.6641 & 0.7673 & 0.7152 \\
\hline
\end{tabular}

that are on average smaller than incumbents. More precisely, for each industry, we compute the average stock of liquid assets of survived firms $\left(\overline{N W^{k}}\right.$, with $\left.k=j, i\right)$ and we build entrants as random copies of those survived firms that hold a stock of liquid assets smaller than $\zeta \overline{N W^{k}}$, with $0<\zeta \leq 1$. As Table IV shows, simulation results do not substantially change if we progressively reduce the relative size of entrants with respect to incumbents (compare, for instance, Table IV with the top panel of Tables II and III). ${ }^{20}$

We have also checked whether our model is able to match the microeconomic stylized facts on productivity dynamics $(S F 10-11)$. To do so, we compute at each $t$ - the standard deviation of labor productivities across consumption-good firms. Our results (see Dosi, Fagiolo, and Roventini, 2005) indicate that significantly asymmetries persist throughout the history of our simulated economy (in tune with $S F 10$ ). Moreover, we firm-specific productivity auto-correlations turn out to be significantly larger than zero, thus suggesting persistency in micro productivity differentials (cf. $S F 11){ }^{21}$

\section{Conclusions}

In this work, we have begun to explore the properties of an evolutionary, agent-based model wherein macroeconomics dynamics is nested into heterogenous boundedly rational firms which operate in two vertically linked sectors, producing 'machines' and a consumption good. Technical progress is machine-specific and diffuses in the economy via time-consuming investment by users. In turn, investment and production decisions induce demand propagation effects much alike Keynesian 'multiplier' effects. Conversely, adaptive expectations on demand drive investments in manners closely resembling the Keynesian 'accelerator'.

The results, despite the simplicity of the model, appear to be surprisingly in tune with a rather long list of empirical 'stylized facts' - concerning both the properties 
of aggregate variables and the underlying microeconomics. The overall picture stemming from the simulation results is one where self-sustaining, fluctuating patterns of growth emerge out of the interactions among firms operating in market regimes that strongly depart from perfect competition. Firms undergo a permanent process of selection and try to cope - albeit imperfectly - with a turbulent environment characterized by endogenous demand waves and technological shocks. This in turn induces lumpiness in individual firm growth patterns, with relatively frequent episodes of larger- or smaller-than-average growth.

Self-sustained growth comes together with fluctuations in macroeconomic variables characterized by statistical properties similar to the empirically observed one. Interestingly, preliminary investigations appear to suggest that such properties are relatively independent from the specification of expectation formation. Rather, it is the heterogeneity among the agents which is crucial to generate dynamic properties of the model.

Evolutionary microfoundations - in the form of multiple agents, who are imperfectly adaptive in their behavior but also able to innovate - are shown to support macrodynamics with strong Keynesian features.

\section{Appendix: Simulations and System Parameters}

All simulation results presented above refer to the benchmark setup described in Table A-I. Initial conditions are defined as in Table A-II.

Table A-I. Benchmark Parametrization.

\begin{tabular}{llc}
\hline Description & Symbol & Value \\
\hline Size of Consumption-good Industry & $F_{1}$ & 200 \\
Size of Capital-good Industry & $F_{2}$ & 50 \\
Econometric Sample Size & $T$ & 600 \\
Replicator Dynamics Coeff. & $\chi_{1,2}$ & -0.5 \\
Competitiveness weights & $\omega_{1,2,3,4}$ & 1 \\
Uniform Distribution Support: Lower Bound & $\iota_{1}$ & -0.5 \\
Uniform Distribution Support: Upper Bound & $\iota_{2}$ & 0.5 \\
Labor Supply Growth Rate & $\eta$ & 0.01 \\
Wage Setting: $\Delta c p i$ weight & $\psi_{1}$ & 0.75 \\
Wage Setting: $\Delta \bar{A}$ weight & $\psi_{2}$ & 1 \\
Wage Setting: $\Delta U$ weight & $\psi_{3}$ & 0.1 \\
Desired level of capacity utilization & $u^{d}$ & 0.75 \\
Trigger rule & $\alpha$ & 0.1 \\
Payback Period Parameter & $b$ & 4 \\
Mark-up rule & $\mu$ & 0.3 \\
Interest rate & $r$ & 0.01 \\
Wage share & $\varphi$ & 0.1 \\
\hline
\end{tabular}


Table A-II. Initial Conditions.

\begin{tabular}{llr}
\hline Description & Symbol & Value \\
\hline Market Wage & $w(0)$ & 100 \\
Consumer Price Index & $c p i(0)$ & 1.3 \\
Average Labor Productivity & $\bar{A}(0)$ & 100 \\
Liquid Assets & $N W_{i j}(0)$ & 3000 \\
Capital Stock & $K_{j}(0)$ & 2000 \\
Labor Supply & $\mathrm{L}(0)$ & 3000 \\
\hline
\end{tabular}

The simulation results we get under different expectation regimes are quiet robust to different expectation parametrizations. The results reported in the paper have been obtained with $\beta_{1}=0.7, \beta_{2}=0.3, \beta_{3,4}=0 ; \beta_{5}=0.25 ; \beta_{6}=1 ; \beta_{7}=0.05$ and $\beta_{8}=0.25$.

\section{Acknowledgement}

Thanks to Andrea Ginzburg, Marco Lippi, Mauro Napoletano, Sandro Sapio, Leigh Tesfatsion, and an anonymous referee, for their stimulating and helpful comments. All usual disclaimers apply.

\section{Notes}

${ }^{1}$ In recent refinements, the size of the shocks might be lower (King and Rebelo, 1999), but the basic story remains rather unbelievable.

${ }^{2}$ More on evolutionary and 'agent-based computational economics' (ACE) approaches in economics is in Dosi and Nelson (1994), Dosi and Winter (2002), Epstein and Axtell (1996) and Tesfatsion (1997).

${ }^{3}$ See for instance Stock and Watson (1999).

${ }^{4}$ Notice that the following aggregate regularities are fairly robust to diverse, relatively sophisticated statistical analyses. Cf. for example Stock and Watson (1999), Agresti and Mojon (2001) and Napoletano, Roventini, and Sapio (2006), who employ a bandpass filter (based on Baxter and King, 1999 ) to US data ranging from $1956 Q 1$ to $1996 Q 4$, EMU series going from $1970 Q 1$ to $2000 Q 3$, and Italian/U.S. data for the period 1970Q1 - 2002Q3, respectively. See also Kydland and Prescott (1990) who apply a HP filter to US data from $1954 Q 1$ to $1989 Q 4$.

${ }^{5}$ Agresti and Mojon (2001) find that consumption is slightly leading in the EMU area. Napoletano, Roventini, and Sapio (2006) obtain the same result with US data and also find that investment is slightly lagging in Italy. However, since these differences stem from very small changes in the cross-correlation structure, they may just depend on the filter employed to detrend the series.

${ }^{6}$ See Hubbard (1998) for a survey.

${ }^{7}$ See, among others, Fazzari and Athey (1987) and Bond and Meghir (1994). For an alternative point of view, cf. Kaplan and Zingales (1997) and Erickson and Whited (2000).

${ }^{8}$ Note that some subsequent models do analyze the properties of economic fluctuations (Silverberg and Lehnert, 1994; Fagiolo and Dosi, 2003). However, the latter are just the outcome of some underlying 'Schumpeterian' dynamics of innovation and imitation. 


\section{AN EVOLUTIONARY MODEL OF ENDOGENOUS BUSINESS CYCLES}

${ }^{9}$ See Caballero (1999) for a discussion. Cf. also Blinder and Maccini (1991) for a survey of (S,s) inventory behavior models.

${ }^{10}$ An exception is in Thomas (2002). She develops a real business cycle model where firms take their investment decisions according to a (S,s) rule. However, in this model, lumpy investment does not have any significant impact at the macro level, because households preferences for smooth consumption paths sterilize investment lumpiness through price movements (i.e. real wage and interest rate).

${ }^{11}$ This in line with empirical evidence discussed in Feldstein and Foot (1971), Eisner (1972), Goolsbee (1998), who show that replacement investment is typically not proportional to the capital stock.

${ }^{12}$ All updating steps are carried out using a 'parallel updating scheme'. More specifically, all firms have simultaneously access to the updating step and base their decisions on the most recent observation of the variables affecting their updating decision.

${ }^{13} \mathrm{We}$ assume that there are no secondary markets for capital goods. Hence, firms have no incentives to reduce their capital stock.

${ }^{14}$ In both consumption- and capital-good markets, a firm dies if its market share ceases to be positive and market shares of the remaining firms are correspondingly re-adjusted (cf. Dosi et al., 1995).

${ }^{15}$ On the 'methodology' of evolutionary/ACE models, see Nelson and Winter (1982), Lane (1993a,b), Kwasnicki (1998), Dosi and Winter (2002), Pyka and Fagiolo (2005).

${ }^{16}$ See Dosi, Fagiolo, and Roventini (2005) for a discussion of the properties of alternative filtering techniques.

${ }^{17}$ We employ consumption-good firm sales $(S)$ as a proxy of firm size and we normalize each observation by the year-average of firm size in order to remove any time trends in our data. This allows one to get stationary size and growth distributions across years and to safely pool normalized size distributions. For a similar approach see, among others, Bottazzi, Cefis, and Dosi (2002).

${ }^{18}$ On the theory and empirics of Subbotin fits of firm growth rate distributions, see Bottazzi and Secchi (2003a,b).

${ }^{19}$ All results refer to the choice of $T=600$, cf. Appendix A. This econometric sample size is sufficient to allow for convergence of recursive moments of all statistics of interest.

${ }^{20}$ Since the net entry rate is zero by definition, an increasing labor supply should force either the unemployment rate or the average firm size to growth. We find instead that the unemployment rate is always smaller than one and follows a stationary process, whereas the average firm size grows over time. Note that the normalization of firm sizes in all our estimates prevent the latter property to bias firm size distributions.

${ }^{21}$ More precisely, in the last 100 periods of the simulations, we consider the normalized productivity of firms that survived for at least 40 periods and we compute auto-correlations until lag 6 .

\section{References}

Agresti, A. and Mojon, B. (2001). Some stylized facts on the euro area business cycle, Working Paper 95, European Central Bank.

Bartelsman, E. and Doms, M. (2000). Understanding productivity: Lessons from longitudinal microdata. Journal of Economic Literature, 38, 569-594.

Baxter, M. and King, R. (1999). Measuring business cycle: Approximate band-pass filter for economic time series. Review of Economics and Statistics, 81, 575-593.

Blinder, A. and Maccini, L. (1991). Taking stock: A critical assessment of recent research on inventories. Journal of Economic Perspectives, 5, 73-96.

Bond, S. and Meghir, C. (1994). Dynamic investment models and the firms financial policy. Review of Economic Studies, 61, 197-222.

Bottazzi, G., Cefis, E. and Dosi, G. (2002). Corporate growth and industrial structures: Some evidence from the Italian manufacturing industry. Industrial and Corporate Change, 11, 705-723. 
Bottazzi, G. and Secchi, A. (2003a). Common properties and sectoral specificities in the dynamics of U.S. manufacturign firms. Review of Industrial Organization, 23, 217-232.

Bottazzi, G. and Secchi, A. (2003b). Why are distribution of firm growth rates tent-shaped? Economic Letters, 80, 415-420.

Burns, A.F. and Mitchell, W.C. (1946). Measuring Business Cycles. New York, NBER.

Caballero, R. (1999). Aggregate investment in Taylor, J. and M. Woodford (eds.). Handbook of Macroeconomics. Amsterdam, Elsevier Science.

Chiaromonte, F. and Dosi, G. (1993). Heterogeneity competition and macroeconomic dynamics. Structural Change and Economic Dynamics, 4, 39-63.

Cyert, R. and March, J. (1989). A Behavioral Theory of the Firm. 2nd edition, Cambridge, Basil Blackwell.

Doms, M. and Dunne, T. (1998). Capital adjustment patterns in manufacturing plants. Review Economic Dynamics, 1, 409-429.

Dosi, G. (1988). Sources procedures and microeconomic effects of innovation. Journal of Economic Literature, 26, 126-171.

Dosi, G. and Egidi, M. (1991). Substantive and procedural uncertainty: An exploration of economic behaviours in changing environments. Journal of Evolutionary Economics, 1, 145-168.

Dosi, G., Fabiani, S., Aversi, R. and Meacci, M. (1994). The Dynamics of international differentiation: a multi-country evolutionary model. Industrial and Corporate Change, 3, 225-242.

Dosi, G., Fagiolo, G. and Roventini, A. (2005). Animal spirits, lumpy investment and Endogenous Business Cycles", Working Paper 2005/04, Laboratory of Economics and Management (LEM), Sant'Anna School of Advanced Studies, Pisa, Italy.

Dosi, G., Freeman, C. and Fabiani, S. (1994). The process of economic development: Introducing some stylized facts and theories on technologies, firms and institutions. Industrial and Corporate Change, 3, 1-45.

Dosi, G., Marengo, L. and Fagiolo, G. (2005). Learning in evolutionary environment. in Dopfer, K. (ed.), Evolutionary Principles of Economics. Cambridge, Cambridge University Press.

Dosi, G., Marsili, O., Orsenigo, L. and Salvatore, R. (1995). Learning, market selection and the evolution of industrial structures. Small Business Economics, 7, 411-36.

Dosi, G. and Nelson, R. (1994). An introduction to evolutionary theories in economics. Journal of Evolutionary Economics, 4, 153-172.

Dosi, G. and Winter, S. (2002). Interpreting economic change: Evolution, structures and games in Augier, M. and J. March (eds.). The Economics of Choice, Change, and Organizations. Cheltenham, Edward Elgar Publishers.

Eisner, R. (1972). Components of capital expenditures: Replacement and modernization versus expansion. Review of Economics and Statistics, 54, 297-305.

Epstein, J. and Axtell, R. (1996). Growing Artificial Societies: Social Science from the Bottom-Up. Washington D.C., MIT Press.

Erickson, T. and Whited, T. (2000). Measurement error and the relationship between investment and q. Journal of Political Economy, 108, 1027-1057.

Fagiolo, G. and Dosi, G. (2003). Exploitation, exploration and innovation in a model of endogenous growth with locally interacting agents. Structural Change and Economic Dynamics, 14, 237273.

Fazzari, S. and Athey, M. (1987). Asymmetric information, financing constraints, and investments. Review of Economics and Statistics, 69, 481-487.

Fazzari, S., Hubbard, R. and Petersen, B. (1988). Financing constraints and corporate investment. Brookings Papers on Economic Activity, 1, 141-195.

Feldstein, M. and Foot, D. (1971). The other half of gross investment: Replacement and modernization expenditures. Review of Economics and Statistics, 53, 49-58.

Freeman, C. (1982). The Economics of Industrial Innovation. London, Francis Pinter. 


\section{AN EVOLUTIONARY MODEL OF ENDOGENOUS BUSINESS CYCLES}

Goolsbee, A. (1998). The business cycle, financial performance, and the retirement of capital goods", Working Paper 6392, NBER.

Greenwald, B. and Stiglitz, S. (1993). Financial market imperfections and business cycles. Quarterly Journal of Economics, 108, 77-114.

Hubbard, R. (1998). Capital-market imperfections and investment. Journal of Economic Literature, 36, 193-225.

Kaplan, S. and Zingales, L. (1997). Do investment-cashflow sensitivities provide useful measures of financing constraints?. Quarterly Journal of Economics, 112, 169-215.

Katona, G. and Morgan, J.N. (1952). The quantitative study of factors determining business decisions. Quarterly Journal of Economics, 66, 67-90.

King, R. and Rebelo, S. (1999). Resuscitating real business cycles. in Taylor, J. and M. Woodford (eds.), Handbook of Macroeoconomics. Amsterdam, Elsevier Science.

Kirman, A. (1989). The intrinsic limits of modern economic theory: the emperor has no clothes. Economic Journal, 99, 126-139.

Kirman, A. (1992). Whom or what does the representative individual represent? Journal of Economic Perspectives, 6, 117-136.

Kuznets, S. (1930). Secular Movements in Production and Prices. Boston, Houghton Mifflin.

Kwasnicki, W. (1998). Simulation methodology in evolutionary economics. in Schweitzer, F. and G. Silverberg (eds.), Evolution and Self-Organization in Economics. Berlin, Duncker \& Humbold.

Kydland, F. and Prescott, E. (1990). Business cycles: Real facts and a monetary myth. Federal Reserve of Minneapolis Quarterly Review, Spring 1990, 3-18.

Lane, D.A. (1993a). Artificial worlds and economics, part I. Journal of Evolutionary Economics, 3, 89-107.

Lane, D.A. (1993b). Artificial worlds and economics, Part II. Journal of Evolutionary Economics, 3, 177-97.

Mankiw, G.N. and Romer, D. (eds.) (1991). New Keynesian Economics, Cambridge MA, MIT Press.

Modigliani, F. and Miller, M. (1958). The cost of capital, corporation finance and the theory of investment. American Economic Review, 48, 261-297.

Napoletano, M., Roventini, A. and Sapio, S. (2006). Are business cycles all alike? a bandpass filter analysis of the Italian and US cycles. Rivista Italiana degli Economisti, Forthcoming.

Nelson, R. (1981). Research on productivity growth and productivity difference: Dead ends and new departures. Journal of Economic Literature, 19, 1029-1064.

Nelson, R. and Winter, S. (1982). An Evolutionary Theory of Economic Change. Cambridge, The Belknap Press of Harvard University Press.

Pyka, A. and Fagiolo, G. (2005). Agent-based modelling: A methodology for neo-schumpeterian economics. in Hanusch, H. and A. Pyka (eds.), The Elgar Companion to Neo-Schumpeterian Economics. Cheltenham, Edward Elgar Publishers.

Rosenberg, N. (1982). Inside the Blackbox. Cambridge, Cambridge University Press.

Rosenberg, N. (1994). Exploring the Black Box: Technology, Economics and History. Cambridge, Cambridge University Press.

Silverberg, G. and Lehnert, D. (1994). Growth fluctuations in an evolutionary model of creative destruction. in Silverberg, G. and L. Soete (eds.), The economics of growth and technical change. Cheltenham, Edward Elgar.

Solow, R.M. (1956). A contribution to the theory of economic growth. Quarterly Journal of Economics, 70: 65-94.

Stadler, G.W. (1994). Real business cycles. Journal of Economic Literature, 32 (4), 1750-1783.

Stock, J. and Watson, M. (1999). Business cycle fluctuations in U.S. macroeconomic time series. in Taylor, J. and M. Woodford (eds.), Handbook of Macroeconomics. Amsterdam, Elsevier Science. 
G. DOSI, G. FAGIOLO AND A. ROVENTINI

Tesfatsion, L. (1997). How economists can get ALife. in Arthur, W., S. Durlauf and D. Lane (eds.), The Economy as an Evolving Complex System II. Santa Fe Institute, Santa Fe and Reading, MA, Addison-Wesley.

Thomas, L. (2002). Is lumpy investment relevant for business cycle? Journal of Political Economy, 110, 508-534.

Zarnowitz, V. (1985). Recent works on business cycles in historical perspectives: A review of theories and evidence. Journal of Economic Literature, 23, 523-580.

Zarnowitz, V. (1997). Business cycles observed and assessed: Why and how they matter. Working Paper 6230, NBER. 